\title{
Multiple coronary fistulae into left ventricle as an uncommon cause of myocardial ischemia
}

\author{
Anastasia O. Averkova ${ }^{1}$, Kirill A. Savostyanov ${ }^{2}$, Dmitry V. Privalov ${ }^{1,2}$, Victoria A. Brazhnik ${ }^{1,2}$ and Dmitry A. Zateyshchikov ${ }^{1,2}$ \\ ${ }^{1}$ Central State Medical Academy of Department of Presidential Affairs, department of cardiology and internal diseases, Moscow, Russia \\ ${ }^{2}$ City clinical hospital \#51 of State healthcare agency, Moscow, Russia
}

\begin{abstract}
A 59-year-old man with history of hypertension and smoking was admitted to our hospital due to palpitation, progressive exertion angina and dyspnea, which appeared two weeks before. Rest echocardiography demonstrated left ventricular (LV) posterolateral hypokynesis. Treadmill test result showed capacity of 4,6 METS with development of anginal symptoms and frequent premature ventricular contractions (PVC). Stress echo showed increase of posterolateral hypokynesis, inferior hypokynesis. Multiple coronary artery fistulae draining into the LV originating from the distal segments of left anterior descending and diagonal artery, from obtuse marginal branch and from the distal segments of posterior descending and posterior lateral branches of the right coronary artery without any atheroma or stenotic lesion were found during coronary angiography. Clinical and ECG ischemia signs resolved on the treatment which included bisoprolol, amlodipine, perindopril. On-treatment rest and stress echocardiography showed no more hypokynesis.
\end{abstract}

What makes this case unusual is that a patient with an uncommon cause of ischemia showed good response to standard antianginal treatment which has been demonstrated before only in single reports.

\section{Introduction}

A coronary artery fistula $(\mathrm{CF})$ is a communication between one of the coronary arteries and a cardiac chamber or vein. They are usually congenital, but rarely may be acquired due to trauma, after cardiac surgery or angioplasty, or very rarely, because of coronary aneurysm rupture $[1,2]$. Coronary artery fistulas are present in $0.002 \%$ of the general population and are visualized in nearly $0.25 \%$ of patients undergoing catheterization $[3,4]$.

The right and left coronary arteries are involved in 55 and 35\% of cases, respectively; and both vessels are involved in a few [5]. More than $90 \%$ of fistulas open into right heart chambers or their connecting vessels. True fistulas to the veins themselves (coronary sinus or its major branches or venae cava) are uncommon. Thus, about $40 \%$ connect to the right ventricle, $25 \%$ to right atrium, $15 \%$ to $20 \%$ to pulmonary artery, $7 \%$ to coronary sinus, and only $1 \%$ to superior vena cava. Fistulas to the LV are very rare, with an incidence of only $3 \%$ [6,7]. A link between CF to left ventricle (LV) and ischemia has been shown only in several reports [8-10]. This report describes three-vessel involvement of coronary artery fistulas to LV associated with transient myocardial ischemia.

\section{Case report}

A 59-year-old man was admitted to our hospital due to palpitation, progressive exertion angina and dyspnea, which appeared two weeks before. His medical history included hypertension and smoking for 30 years. A week before admission the patient was examined on outpatient basis. The rest echocardiography demonstrated left ventricular posterolateral hypokynesis. Treadmill test result showed capacity of 4,6 METS with development of anginal symptoms and frequent premature ventricular contractions (PVC) (Figure 1). Stress echo revealed increase in posterolateral hypokynesis, appearance of inferior hypokynesis. On physical examination at admission his pulse rate was $80 \mathrm{bpm}$ and his blood pressure was $110 / 70 \mathrm{~mm} \mathrm{Hg}$. Laboratory values included hemoglobin $164 \mathrm{~g} / \mathrm{l}$, total cholesterol $5,5 \mathrm{mmol} / \mathrm{l}$, low-density-lipoprotein cholesterol 3,3 mmol/l, creatinine $86 \mu \mathrm{mol} / \mathrm{l}$. Electrocardiography at rest showed sinus rhythm and no ST segment changes (Figure 2). The patient was suspected to have coronary artery disease. Multislice computed tomography coronary angiography showed enlargement of all coronary arteries and normal coronary veins structure (Figure 3).

The patient underwent cardiac catheterization. There was no atheroma or stenotic lesion, but a heavy stream of contrast agent entered the LV via distal segments of both the left and right coronary arterial systems. The angiogram showed multiple coronary artery fistulas. Two fistulas originated from the distal segments of left anterior descending artery and diagonal artery, another from obtuse marginal branch (Figure 2) and two more from the distal segments of posterior

Correspondence to: Anastasia O. Averkova, MD, Central State Medical Academy of Department of Presidential Affairs, department of cardiology and internal diseases, Moscow, Russia, Leninskiy prospect 64/2, 391, 119296, Tel: 0079161624607; E-mail: averkovaao@gmail.com

Key words: coronary fistula, uncommon cause of ischemic

Special Issue: Imaging of myocardial diseases: to new horizons

Valentin E. Sinitsyn

Professor

Department of Radiology

Federal Center of Medicine and Rehabilitation

Russia

E-mail: vsini@mail.ru

Published: July 30, 2016 


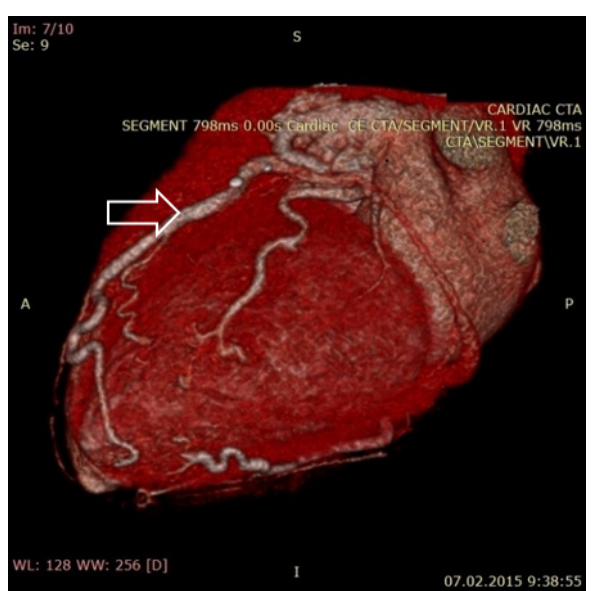

Figure 1. Multislice computed tomography angiography showing enlarged coronary arteries.

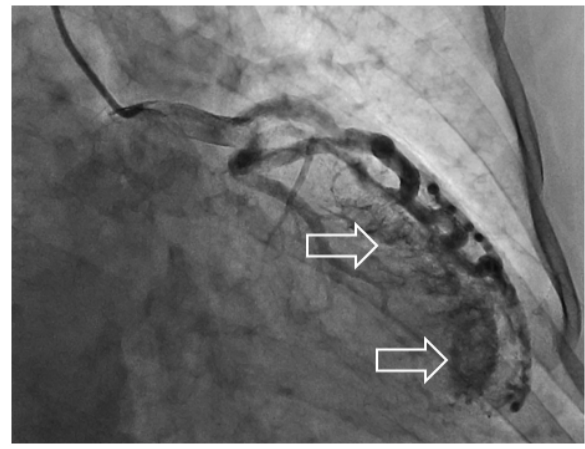

Figure 2. Coronary angiography showing left coronary artery fistulae.

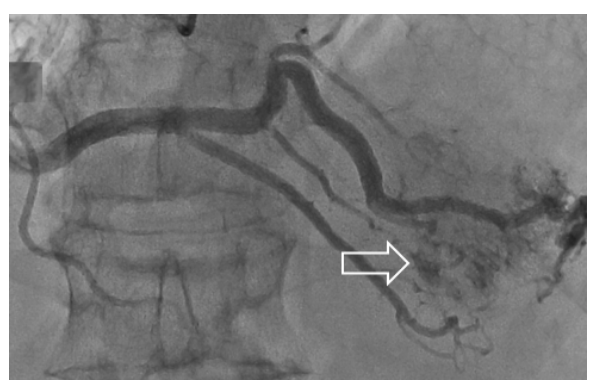

Figure 3. Coronary angiography showing right coronary artery fistulae.

descending and posterior lateral branches of the right coronary artery (Figure 1). All fistulae were seen draining into the LV. The patient had not received any treatment before admission. Afterwards he started treatment with bisoprolol, amlodipine and perindopril. On the treatment clinical symptoms including palpitation, chest pain and dyspnea resolved. 24 hours ECG monitoring showed 15 single PVC and no ischemic ST segment changes. On-treatment rest and stress echocardiography showed no more hypokynesis.

\section{Discussion}

Most fistulas are small and asymptomatic. They are usually discovered incidentally during coronary angiography or during screening for an asymptomatic cardiac murmur. However, fistulas can be symptomatic, particularly larger fistulas. The intracoronary diastolic perfusion pressure diminishes progressively whether the fistula is large.
Congestive heart failure, dyspnea, arrhythmias, myocardial ischemia/ infarction, pulmonary hypertension, infective endocarditis, aneurysm formation, coronary rupture, and death could be sign of this congenital anomaly. The pathophysiology thought to be myocardial stealing or reduction in myocardial blood flow distal to the site of the fistula. The mechanism is related to the diastolic pressure gradient and runoff from the coronary vasculature to the low-pressure receiving cavity. There is data that beta-blockers provoke decrease in coronary collateral flow [11] so we can speculate the same mechanism in the case of coronary fistulas. This may be associated with a reduction in myocardial oxygen consumption and longer diastolic filling time induced by the decrease in the rate-pressure product.

Because fistulas enlarge over the time, this can explain why only $10 \%$ of patients younger than 20 years have complaints. Patients older than 20 years have complaints in $35 \%$ of cases [12-15].

The best way to manage cameral fistulas is uncertain largely due to the rarity of the condition. Depending on the size and location of the fistula, epicardial and endocardial surgical ligation or percutaneous endoluminal embolisation may be performed. Intervention is difficult when fistulae are diffuse; therefore despite ischemia in our case percutaneous intervention was not performed [16].

What makes this case unusual is that a patient with complaints of palpitation, dyspnea, angina and an uncommon cause of ischemia showed good response to standard antianginal treatment which before has been demonstrated only in a few reports [17].

\section{References}

1. Blaschke F, Baur A, Roser M, Attanasio P, Ozcelik C, et al. (2012) Absent proximal right coronary artery with a fistula into the pulmonary vein. Europace 14: 1369-1370. [Crossref]

2. Gupta A, Saxena S (2012) Acquired (post-angioplasty) coronary ventricular fistula draining into left ventricle aneurysm. J Invasive Cardiol 24: E99-100.[Crossref]

3. Luo L, Kebede S, Wu S, Stouffer GA (2006) Coronary artery fistulae. Am J Med Sci 332: 79-84.[Crossref]

4. Dresios C, Apostolakis S, Tzortzis S, Lazaridis K, Gardikiotis A(2010) Apical hypertrophic cardiomyopathy associated with multiple coronary artery-left ventricular fistulae: a report of a case and review of the literature. Eur J Echocardiogr 11: E9. [Crossref]

5. Braunwald E (2005)Braunwald's Heart Disease. (7thedn), New York: Elsevier.

6. Chen JP, Rodie J (2009) Bi-directional flow in coronary-to-left ventricular fistula. Int J Cardiol 133: e41-42.[Crossref]

7. Mangukia CV (2012) Coronary artery fistula. Ann Thorac Surg 93: 2084-2092. [Crossref]

8. Uyar IS, Akpinar B, Senarslan O, Sahin V, Uc H (2015) Multiple coronary fistulae to left ventricle, with acute myocardial infarction. Asian Cardiovasc Thorac Ann 23: 561-563. [Crossref]

9. Arslan S, Gurlertop Y, Elbey MA, Karakelleoglu S (2009) Multiple coronary-cameral fistulae causing angina pectoris. Tex Heart Inst $J$ 36: 622-623. [Crossref]

10. Strange JW, Bucciarelli-Ducci C, Mathur A, Pennell DJ (2008) Images in cardiovascular medicine. Multiple coronary fistulae: a cause of subendocardial ischemia. Circulation 117: 853-856.[Crossref]

11. Billinger M, RaeberL, Seiler C, Windecker S, Meier B, et al. (2004) Coronary collatera perfusion in patients with coronary artery disease: effect of metoprolol. Eur Heart J 25: 565-570.[Crossref]

12. Kouchoukos NT, Blackstone EH, Doty DB, HanlyFL, Karb RB(2003) Congenita anomalies of the coronary arteries: coronary arterovenous fistula. In:Kirklin, BarrattBoyes Cardiac Surgery, 1241-1242, Churchill Livingstone, New York, NY, USA, 3rd edition.

13. Brickner ME, Hillis LD, Lange RA (2000) Congenital heart disease in adults. Second of two parts. $N$ Engl J Med 342: 334-342.[Crossref] 
14. Burns KE, Ferguson KA, Spouge A, Brown JE (2001) Massive congenital coronary arteriovenous malformation presenting with exertional dyspnea and desaturation in an adult: a case report and review of the literature. Can J Cardiol 17: 85-89.[Crossref]

15. Misumi T, Nishikawa K, Yasudo M, Suzuki T, Kumamaru H (2001) Rupture of an aneurysm of a coronary arteriovenous fistula. Ann Thorac Surg 71: 2026-2027. [Crossref]
16. Iyisoy A, Arslan Z, Ozmen N, Kurşaklioğlu H, Amasyali B, et al. (2003) Double coronary fistulas between coronary artery and left ventricle. A case report (in Turkish). Gulhane Tip Dergisi 45:203-205.

17. Higuchi H, Takeuchi M, Fujioka H, Shiozaki A, Tanaka T, et al. (1989) [A case of coronary artery fistula with angina pectoris]. Kokyu To Junkan 37: 1139-1141.[Crossref]

Copyright: $\bigcirc 2016$ Averkova AO. This is an open-access article distributed under the terms of the Creative Commons Attribution License, which permits unrestricted use, distribution, and reproduction in any medium, provided the original author and source are credited. 